\title{
The Embodied Self and the Paradox of Subjectivity
}

\section{Christoph Durt $^{1}$ (D)}

Published online: 6 November 2019

(c) The Author(s) 2019

\begin{abstract}
While it seems obvious that the embodied self is both a subject of experience and an object in the world, it is not clear how, or even whether, both of these senses of self can refer to the same self. According to Husserl, the relation between these two senses of self is beset by the "paradox of human subjectivity." Following Husserl's lead, scholars have attempted to resolve the paradox of subjectivity. This paper categorizes the different formulations of the paradox according to the dimension each pertains to and considers the prospects of each proposed resolution. It will be shown that, contrary to the claims of the respective authors, their attempted resolutions do not really resolve the paradox, but instead rephrase it or push it to the next dimension. This suggests that there is something deeper at work than a mere misunderstanding. This paper does not aim to resolve the paradox but instead initiates a new approach to it. Instead of seeing the paradox as a misapprehension that needs to be removed, I dig deeper to reveal its roots in ordinary consciousness. Investigating the proposed resolutions will reveal the fundamental role of the natural attitude, and I will argue that already the general thesis of the natural attitude makes the decisive cut that leads to what Sartre calls a "fissure" in pre-reflective self-awareness. The phenomenological reduction deepens the cut into what Husserl calls the "split of the self," which in turn engenders the paradox of subjectivity. The paradox's roots in the structure of ordinary consciousness not only constitute a reason for its persistence, but also suggest a new way to further investigate the embodied self.
\end{abstract}

\section{Introduction}

The embodied self is, at the same time, subjectively aware of the world, and objectively part of the world as a human, animal, or other being. The self in the first sense will here be called "subject for the world" and in the second "object in the world." But can these two senses of self even refer to the same thing? Defining the self in terms of subjective awareness seems to imply that the self is not part of the world in

Christoph Durt

Christoph@Durt.de

1 University of Vienna, Universitätsstraße 7 (NIG), 1010 Vienna, Austria 
the same sense that material objects are part of the world. Meanwhile, defining the self as an object in the world seems to imply that the self is part of the world and not a subject to whom the world is given. In The Crisis of European Sciences and Transcendental Phenomenology, Husserl contends that the concept of self engenders a paradox, the "paradox of human subjectivity: being a subject for the world and at the same time being an object in the world" (1970, p. 178). But what exactly is the paradox of subjectivity, and what gives rise to it? Can the two senses of self even refer to the same self, and if so, how are they related to each other? Getting clearer about their relation matters for any account of the self that aims to make sense of both the subjective and the objective sense of selfhood, such as an embodied account of the self, or perhaps a "multidimensional account" (Zahavi 2014, p. 90).

Husserl offers some especially rich reflections on the paradox of subjectivity, but the problem of the relation between the self as an object in and a subject for the world is by no means peculiar to the phenomenological tradition. Similar formulations of this problem have been provided by in other respects very different philosophers. Kant contended that the thought "I am conscious of myself, is a thought that contains a twofold I, the I as subject and the I as object." To the question of "how it is possible that I, who thinks, can be an object (of intuition) for myself, and in that way distinguish me from myself," he gives the quite unsatisfactory answer that it "is simply impossible to explain, even though it is an undoubted fact" (1942, p. 270). The paradox of subjectivity consists here in the juxtaposition of two claims. On the one hand, the assertion that it is a fact that self-consciousness necessarily comprises the I as subject and the I as object. On the other hand, the claim that it is "simply" impossible to explain how the I as a subject can be an object for oneself. Even if Kant is right that this is impossible, however, we may ask whether it suffices to state that this is "simply" so, or whether this impossibility of explanation could itself be explained. In this paper I will argue that there is indeed a reason why the paradox of subjectivity cannot be completely resolved.

In the analytic tradition, a well-known example of the problem of the relation between the two senses of self is exhibited in Thomas Nagel's The View from Nowhere, the introduction of which begins with the statement: "This book is about a single problem: how to combine the perspective of a particular person inside the world with an objective view of that same world, the person and his viewpoint included" (Nagel 1986, p. 3). The problem can here be stated in terms of perspectives or viewpoints: how can these two viewpoints be combined if one is the subjective view which someone has of the whole world, and the other is the viewpoint which includes that person as part of the world? Nagel's first formulation refers to the self: the person inside the objective world, and the subjective perspective one has of the world. Nevertheless, for him, the problem concerns not only the concept of self, but also the concept of consciousness in general. Nagel also speaks of "viewpoints" and "standpoints" that are either internal and external, or subjective and objective. He speaks of "distinct and irreducible perspectives," of "first- and third-person ascription," as well as other oppositions, each of which he finds hard or impossible to reconcile. Thus the "single problem," as Nagel puts it, is not limited to one distinction, but rather manifests itself in a number of puzzles concerning core issues of philosophy. 
In contrast with Nagel's first formulation of the "single problem," Husserl's first formulation of the paradox, as cited above, which comes from the heading of his discussion of the paradox, does not refer to the relation between the "I," ego, or self as subject for and as object in the world. ${ }^{1}$ Husserl's formulation instead concerns the dimension of "universal intersubjectivity, into which all objectivity, everything that exists at all, is resolved" (1970, p. 179). The constitution of objectivity is here thought of as something that is done in a community of beings. He writes that universal intersubjectivity "can obviously be nothing other than mankind; and the latter is undeniably a component part of the world" (1970, p. 179). Here the paradox is due to the idea that universal intersubjectivity constitutes the world and yet is also a part of what it constitutes. It seems as if universal intersubjectivity constitutes itself, which seems absurd. The paradoxical relation between the two senses of self comes into play not in Husserl's first formulation of the problem, but in his first attempt to resolve the problem.

Even just with respect to the self, there are various possible interpretations of what the paradox is, and how it is conceived determines our options for dealing with it. Clearly, there is no agreement on this among leading scholars of Husserl. Some have claimed that there is a paradox only if the relation between the two notions of self is interpreted ontically. The paradox has been claimed to vanish when the relation is interpreted epistemically (Seebohm 2015, p. 39), or once it is recognized that there are merely two different viewpoints on one and the same thing (Luft 2012, p. 249). In contrast, David Carr, in his book The Paradox of Subjectivity, contends that "[t]hese two descriptions of the subject—subject for the world and object in the world - are equally necessary and essentially incompatible" (1999, p. 135). Others have claimed that the paradox does not entail any contradiction or incompatibility for transcendental phenomenology (Drummond 2002), and that phenomenological reflection does not "eliminate the difference between the transcendental and the empirical perspective, but perhaps it makes their coexistence less paradoxical" (Zahavi 2002, p. 109). Another view is that "[t]he paradox cannot be resolved but only ('subjectively') re-enacted" (Rinofner-Kreidl 2003, p. 131; my translation).

To disentangle the character and implications of the paradox of subjectivity, I will distinguish between several dimensions of the paradox: universal intersubjectivity, grammatical equivocation, the ontic interpretation, the epistemic interpretation, the relation between the descriptions from the natural and the phenomenological attitude, and embodiment. I will show that each attempt at resolution does not truly eliminate the paradox, but at best pushes it into the next dimension. One may even speak of different paradoxes of human subjectivity, but that would make it harder to see that they all concern, in analogous ways, the same kind of relation, and therefore express different aspects of one and the same puzzle. This paper digs beneath the surface of conceptual confusion and seeks the roots of the paradox of subjectivity in ordinary consciousness. I will argue that ultimately the paradox of subjectivity cannot be completely resolved because it is rooted in the structure of ordinary conscious experience itself, rather than in any mere conceptual misunderstanding.

\footnotetext{
${ }^{1}$ For the purpose of this paper "I," "self," and "ego" will mostly be understood as synonyms.
} 


\section{The Paradox in the Dimension of Universal Intersubjectivity and as an Equivocation}

Broadly speaking, the paradox of subjectivity concerns the relationship of subjectivity or consciousness to the world. On the one hand, subjectivity constitutes or discloses objects, in the sense they have for us as conscious beings. On the other hand, subjectivity pertains to humans who are, of course, objects in the world. But these two claims do not seem to fit together well, although it is not immediately obvious what exactly the problem is. If everything in the world is constituted by subjectivity, then subjectivity also constitutes humans, including their subjectivity. But that seems absurd. Husserl writes metaphorically that "[t]he subjective part of the world swallows up, so to speak, the whole world and thus itself too. What an absurdity!" (1970, p. 180). Metaphorical language can help us to get a first impression of the problem, but it is not sufficiently precise for a clear description. Starting right away with a precise definition, however, would presuppose a specific interpretation of the paradox. And that would be inappropriate for understanding Husserl's account, because there are different formulations of the paradox of subjectivity in Husserl's writings. Furthermore, it would preclude the possibility that the paradox persists through different dimensions: a persistence that will be seen through the following sections.

Husserl's expression "what an absurdity!" suggests that he meant his metaphor ironically, and that at this point he thought he could easily resolve the paradox of subjectivity. Accordingly, after speaking about the paradox in the dimension of "universal intersubjectivity" (1970, p. 179), Husserl immediately endeavors to overcome the paradox under the promising headline "the resolution of the paradox" (1970, p. 182). This resolution is supposed to eliminate the paradox from the dimension of universal intersubjectivity. Reflecting critically on his earlier work, Husserl admits that, in his investigation of the intersubjective constitution of the world, he had failed to pay sufficient attention to the self. He now tries to rectify that mistake and claims that intersubjectivity itself is constituted, and that in order to understand how it is constituted, we need to consider how it is given to the self. Husserl asserts that once we understand how intersubjectivity is given to the self, we can also understand its relation to the world. His first "resolution" of the paradox, however, produces more questions than answers. If Husserl had first thought that his ironic formulation could easily be dismissed, he subsequently seems to vastly widen the scope of the paradox. Certainly, just as quickly as Husserl attempts to resolve the paradox, he admits that this first attempted resolution is insufficient (1970, p. 184).

He then immediately makes a second attempt to quickly resolve the paradox, but this resolution also remains unfinished. While he firmly asserts that the "I" "constitutes a first sphere of objects" and then "performs a constitutive accomplishment" (1970, p. 185), here he does not explain in sufficient detail how the "I" does so, and postpones the solution of the paradox of subjectivity to future study. The incomplete character of the respective passages of the Crisis not only reveals the external pressure Husserl was under when he wrote them, but also suggest that the paradox of subjectivity defies both a simple definition and an easy resolution. While there is 
little doubt that Husserl thought that transcendental phenomenology must be able to resolve the paradox of subjectivity, the introduction of the self does not by itself resolve the paradox. In fact, the radical difference between the transcendental self and the empirical self, rather than resolving the paradox, can instead be used to reformulate it:

The empirical self stands in a relationship of inclusion to the world-a partwhole relation-whereas the transcendental self is not in the world at all in the sense that the empirical self is; the transcendental self is of or for the world, a subject intentionally related to its object. This double relationship, of course, is precisely the paradox of subjectivity. (Drummond 2002, p. 96)

That the paradox can be formulated in similar terms regarding the self makes clear that introducing the self does not provide a resolution of the paradox in the first place, but at most relocates it. Instead of being eliminated, the paradox of subjectivity is shifted to the relation between the constituting self, on one side, and the constituted self as part of the world, on the other. While it is announced as a resolution to the paradox, Husserl's introduction of the self actually brings to light the main version of the paradox, as discussed by most interpreters of Husserl, concerning the juxtaposition of two notions of self.

Even with respect to the two notions of self, there may be-and are-several formulations of the paradox. But before we bother ourselves with these different formulations, can we not embrace the idea that there are two concepts of self, and yet easily dismiss any appearance of paradox, by stating that the self as a subject is simply a different thing from the self as an object? In a trivial analogy, the word "bat" can be used to denote a species of flying mammal, as well as a club used in baseball, but that doesn't make their relation paradoxical. The word "bat" simply has two different meanings, and taking one homonym for the other would be an equivocation. Analogously, the two descriptions of the self may be the same in name only, but in fact refer to two different kinds of thing. On a quick reading, Husserl does indeed seem to suggest that the source of the paradox lies in such an equivocation between two uses of "I": "[t]he 'I' that I attain in the epoche is actually called 'I' only by equivocation" (1970, p. 184). If there are two independent things, the personal "I" before and the "I" after the epoche, and the latter is the same "I" in name only, and in fact names a completely different thing, then their relation is no more paradoxical than that between any other two merely conventional homonyms.

Simply stating that the two "I"s are homonyms would not be a true "resolution" of the paradox, however, since this would not resolve but rather dodge the problem of the apparent relation between the two senses of self. Whereas the two senses of "bat" do not have any apparent intrinsic relation to each other that would be at odds with the idea that they are the same in name only, this is not true with respect to the two senses of "self." That the two senses of "self" are not only connected by conventional grammar is already suggested by some very basic facts about human life, such as the fact that my sense organs and muscles are in the world and yet co-determine how I, as a subject, can relate to the world. Furthermore, in ordinary experience, the two senses of self are thoroughly integrated. Recognizing oneself in a mirror, for instance, implies somehow recognizing that the object seen in the mirror is also the 
subject who experiences the mirror image. Since the two "I"s appear to be so intimately intertwined, stating that I really experience two independent things that are conventionally conflated would again be paradoxical. Thus this apparent resolution of the paradox of subjectivity is not in fact a genuine resolution, but instead yields a reformulation of the paradox.

For Husserl, it is clear that both senses of self are essentially connected. The first refers to the "I" before and the latter to that after the epoche्e thus both are part of the being that engages in the epoche. Later, in Sect. 5, I will return to the relation between the two "I"s in connection with what in earlier texts Husserl calls a "split" and "duplication" of the self (Hua VIII, pp. 90-91, 410-413). Regarding the equivocation, he speaks of "an essential equivocation since, when I name it in reflection, I can say nothing other than: it is I who practice the epoch $\vec{e}$ " $(1970$, p. 184; Hua XXXIV, p. 286). While the "I" after the epoche is of a very different kind from the "I" that performs the epoche, and in this sense are both called "I" by convention only, they are nevertheless necessarily connected. But this does not resolve the paradox of subjectivity either. If one self is conflated with something else, then they are not both the same self, and saying that this equivocation is essential makes the claim that they are nevertheless necessarily connected no less paradoxical. The essence of the self would now seem to contain two very different kinds of beings. This confronts us with another formulation of the paradox: here there are two different kinds of being, which are nevertheless essentially related. The paradox here pertains to the ontic dimension of two distinct beings. As will be discussed in the next section, some interpreters have claimed that the paradox is correctly interpreted as pertaining to this ontic dimension, and that it can be resolved on this construal.

\section{Ontic Interpretations of the Paradox}

The formulation of the paradox cited above, "being a subject for the world and at the same time being an object in the world," comes from the heading of Husserl's discussion of the paradox (1970, p. 178). Already this heading gives the impression that he thinks that the paradox is due to an ontological distinction. Seebohm claims exactly this: "The formulation of the paradox of subjectivity in the Crisis presupposes the ontic interpretation: being a subject (Subjektsein) for the world and at the same time being an object (Objektsein) in the world" (2015, pp. 38-39, original emphasis). Seebohm emphasizes the compound word part "being" and contends that the paradox is due to the distinction between two ontic "kinds" of being, specifically that of a necessary subject for the world and that of a contingent object in the world (2015, p. 39). Since the self as a subject is supposed to be a necessary being for the world, and at the same time given to itself as a contingent being in the world, it would have to be both a necessary and a contingent being, which would constitute a paradox (2015, p. 39). 
Seebohm claims that the ontic interpretation misunderstands the epoche, or phenomenological reduction, ${ }^{2}$ by illegitimately inferring an ontological distinction from "epistemic categories" (2015, p. 38). The correct understanding of the relation between the two concepts of self would be the "epistemic interpretation" (2015, p. 39), which is concerned with epistemological evidence rather than with ontological kinds of beings. Seebohm repeatedly asserts that "no paradox is involved" (2015, pp. 39, 40, cf. 36) in this epistemic interpretation. But, despite Seebohm's assertions, it is not obvious that his epistemic interpretation completely avoids all versions of the paradox of subjectivity, rather than merely avoiding the paradox in the specific ontic sense he proposes. The fact that Seebohm sees no paradox in his epistemic interpretation does not preclude that (1) there could be other ontic interpretations that are unaffected by the refutation of the specific ontic interpretation proposed by Seebohm. For instance, Sartre speaks of "two absolutely separated regions of being: the being of the pre-reflective cogito and the being of the phenomenon" and nevertheless maintains that we must "explain how these two regions can be placed under the same heading" (2012, p. 1xiii). Sartre's concept of being, which he extensively develops in Being and Nothingness, is more complex than the one Seebohm argues against, and is not as easily dismissed in the same way, that is, by showing that it is inferred from epistemic categories. Furthermore, and more pertinently for the purpose of this paper, (2) the paradox may reappear in the epistemic dimension. In the next section I will argue that this is so for the descriptions from the natural and the phenomenological attitude.

A less specific variant of the ontic interpretation that may be more widely applicable is presented by Sebastian Luft, who interprets the paradox as straightforwardly arising from a misconception. He references the same formulation cited by Seebohm but, without any complicated elaborations, immediately goes on to claim that the paradox vanishes once it is realized that the self in the world is not a different thing from the self for the world:

[T]his paradox vanishes when phenomenologically clarified: the solution is the realization that the subject that experiences the world and is also an object in the world are but two different viewpoints on the same thing. The subject is another object in the world like trees, animals and other humans from the standpoint of the natural attitude, but after the reduction it is revealed as the transcendental subject, i.e. as the sphere of experience in which the world constitutes itself. (Luft 2012, p. 249)

This resolution implies that the paradox arises from the ontic dimension, namely that it is due to assuming the existence of two different things. The paradox is alleged to arise from the mistaken assumption that the self as a subject for the world is one thing, while the self as an object in the world is something else. Thus construed, the paradox seems easily resolved: there are not two things here, but only two different viewpoints on one and the same thing, namely the subject. On the one hand, there is

\footnotetext{
2 Seebohm uses the term "reductio/reduction" synonymously with epoche (2015, p. 13 fn. 9). These concepts will be distinguished in Sect. 4 .
} 
the transcendental viewpoint, from which the subject appears as the "sphere of experience in which the world constitutes itself" (Luft 2012, p. 249). On the other hand, there is the view from the natural attitude, from which the subject appears as an object in the world. This resolution eliminates the paradox in the ontic dimension by postulating that there really is only one thing here, and claiming that the reason it seems as if there were two different things is that there are two different viewpoints on one and the same thing. Like Seebohm's epistemic interpretation, Luft's alleged resolution of the paradox pertains to the epistemic dimension: there are just two viewpoints on one and the same thing.

But does the epistemic interpretation really resolve the paradox of subjectivity? As long as we do not assume that the two descriptions are descriptions of different selves (see Sect. 2), Luft is surely right that the two points of view must pertain to the same thing. But stating that both descriptions denote the same thing does not resolve the paradox. Rather, it is part of the description of the paradox of subjectivity: both viewpoints must concern the same thing, and yet we do not understand how this is even possible. These two viewpoints are obviously more radically distinct than a typical pair of viewpoints on some thing in the world. The self as an object in the world is, just like other objects, in the world, but the self as a subject for the world does not seem to be part of the world in any ordinary sense. So how could the two even be the same thing? In particular, how could a subject possibly be "another object in the world like trees, animals, or other humans"? The epistemic interpretation of the relation between the two senses of self may dismiss such questions as ontological and try to bracket them, but regardless of whether the two viewpoints concern the same "being" or the same "thing," it needs to be clarified how they can do so.

As long as the relation between the viewpoints is not clarified, this apparent resolution is not really a resolution, but rather yields a reformulation of the paradox: how can the two viewpoints possibly have the same subject? In other words, how can the description from the natural attitude be reconciled with that from the phenomenological attitude, if they are so different that they do not even seem to denote the same thing? Even if realizing that these two apparently different things are really one and the same thing eliminates the paradox in the ontic dimension, this does not resolve the paradox in the epistemic dimension of two viewpoints, perspectives, or attitudes. Rather than being resolved, the paradox of subjectivity is merely relocated from the ontic to the epistemic dimension. Here, the question is whether the relation between the description of the self as a subject for the world and that of the self as an object in the world is paradoxical. For phenomenology, this question necessitates an examination of how the phenomenological attitude departs from the natural attitude, which is the task of the next section.

\section{The Paradox Between the Descriptions from the Natural and the Phenomenological Attitude}

To consider the paradox in connection with the phenomenological attitude, it will be fruitful to distinguish between epoche and phenomenological reduction. The epoche alone does not lead to a description that would stand in a paradoxical relation to the 
self in the world. The natural attitude, with its "general thesis," takes for granted that the world exists, and that the objects in it and their properties and relations exist objectively, just as they appear in ordinary experience. Such assumptions do not have to be thematized, thought, or predicated in the natural attitude; they can also be a non-reflective part of experience (Hua III/1, p. 60). Since the epoche "brackets" or "suspends" the general thesis, the epoche is neither concerned with the existence of objects in the world, nor does it doubt the existence of anything. When the epoche suspends all assumptions of existence, it leaves intact ordinary belief in the existence of objects, just without the positing element of doxa, or belief, in the existence (or non-existence) of things. Instead of opposing the description of the self as an object in the world from the natural attitude, the epoche allows the self to be investigated as an object independent of the general thesis and the assumption of worldly existence it involves.

Since the epoche brackets, or suspends, questions of existence, it does not result in a paradoxical relation between two things in the same region of material being. The paradox of subjectivity is not due to the apparent existence of two different things in the world that nevertheless would have to be the same thing. Nor is there any paradox about how the self as an object in the world after the epoche relates to the self as an object in the world before the epoch $\bar{e}$ - the former is still an object, it's just that its factual existence in the world is bracketed. The epoche alone does not disclose the self as a subject for the world, but opens the way for the phenomenological reduction, which, as suggested by its Latin root (re-+ducere), leads the experience of the natural attitude back to its constituents. It thereby unveils the complexity of experience that had previously been overlooked, due to the preoccupation of ordinary experience with identical objects. But the shift of focus to the complexity of experience does not lead to a paradox regarding the object of experience either; it may just show that ordinary experience is overly simplistic. ${ }^{3}$

With respect to the subject of experience, in contrast, the phenomenological reduction does lead to a description of the self that stands in a paradoxical relation to the description of the self in the world. The phenomenological reduction uncovers the subjectivity of experience that belongs to all experiences of a subject, and not just any one individual experience or any one type of experience. It brings to the fore something about experience that does not correspond to any one object in the world. Within the phenomenological attitude, this does not lead to any paradox either, as long as the self as the whole of subjective experience is not identified with any mere part of experience. But when the phenomenological attitude is supposed to

\footnotetext{
${ }^{3}$ For instance, while looking at a colored object, we usually perceive the color as something identical and unchanging, but if we reflect on the mode in which the color appears, "we recognize that the color is nothing other, nor can it be thought as anything other, than that which presents itself now as this and now as that shade of color" (Husserl 1998, p. 16; see also Hua I, p. 17). The description of the color that results from recognizing the diversity of experience is more fine-grained and unveils essential structures of experience. While this contradicts the first impression that experience is simple, it nevertheless sharpens rather than contradicts the more coarse-grained appearance of experience in the natural attitude. In this respect, the phenomenological description doesn't stand in a paradoxical relation to the description of experience from the natural attitude.
} 
refer to the same self as the natural attitude, one's subjectivity of experience is supposed to correspond to a part of the very world it constitutes, which is paradoxical. Because the phenomenological reduction uncovers the self as a subject of experience, it leads to a description of the self that stands in a paradoxical relation to the description of the self from the natural attitude.

Hence Husserl was right to suspect, early on in his discussion of the paradox of subjectivity, that the paradox arises "necessarily out of the constant tension between the power of what is taken for granted in the natural objective attitude (the power of 'common sense') and the opposed attitude of the 'disinterested spectator"' (1970, p. 180). The "disinterested spectator" here does not mark an objective point of view, but is rather the person who brackets the assumptions of existence in the epoche and who is concerned with the phenomena in her or his subjective experience. Earlier on, Husserl also speaks of a "transcendental spectator" (Hua IX, p. 341), and in the next section we will consider this expression in context and study its implications for the paradox of subjectivity. I will argue that the "constant tension" is not merely due to some philosophical method, but that it is instead founded in the structure of ordinary consciousness. Since the phenomenological reduction picks up and sharpens the constituents of ordinary consciousness, the natural and the phenomenological attitude are not merely extrinsically connected, such as by the insight that they must both refer to the same thing. Rather, they are both part of the same being-not a mere object in the world, nor a disembodied point of view on the world, but instead the embodied being who engages in the natural and the phenomenological attitude.

If the two descriptions are not merely parallel, but refer to the same embodied being, then could the concept of embodiment solve the paradox of subjectivity? Drummond holds that the paradox only sometimes entails a contradiction for transcendental philosophy, notably in Kant's transcendental idealism. Kant's "projective" account of the content of intentional experience conceives experience as something internal that then is projected on the outer world (Drummond 2002, p. 94). Kant's account thereby severs the connection between the empirical and the transcendental self, and engenders two contradicting accounts of the self. Husserl's "disclosive" account of the content of intentional experience, in contrast, is not selfenclosed and does not engender any incompatibility or contradiction between the two senses of self (Drummond 2002, p. 99). In Husserl's hands, the two sides are compatible because the "transcendental account makes room within itself for the empirical account" (2002, p. 99). It does so "[b]y recognizing that the consciousness on which we reflect is embodied and by allowing for the fact that our disclosure of the sense of the world has psycho-physical conditions that affect it" (2002, p. 99). Drummond himself does not claim that this could resolve the paradox of subjectivity, and maintains that "subjectivity remains a paradox but not a contradiction" (2002, p. 100). His claim is only that the paradox does not amount to a contradiction for transcendental phenomenology.

I think that Drummond makes a crucial point when he emphasizes the importance of embodiment. He is right to say that the consciousness on which we reflect is embodied, and that once we can clarify how it is embodied, we may find that we have resolved the apparent contradiction between the two descriptions of self. One advantage of embodied concepts of the mind is that they avoid some apparent 
contradictions found in other accounts, such as the one Drummond attributes to Kant. The question is "only" how consciousness is embodied. The embodied self is not only a body in the world in the empirical sense, but also a subject for the world. This cannot simply be stipulated, however. If both belong to the embodied being, it must be clear how this is possible. But now we are once again faced with the original question: how can a being be both a subject for and an object in the world? Because the embodied being must be both a subject for the world and an object in the world, the paradox of subjectivity reappears in the dimension of embodiment. The concept of embodiment does not constitute a simple solution, but, on the contrary, itself needs to deal with the paradox of subjectivity. Yet, in embodied experience, the different constituents of the paradox are united. How this is so will be investigated in the next section, in the context of the relation between ordinary experience and the paradox of subjectivity.

\section{The Roots of the Paradox in Ordinary Consciousness}

In each of the dimensions of the paradox of subjectivity considered above- - universal intersubjectivity, the ontic interpretation, the epistemic interpretation, the natural and phenomenological attitude, and embodiment-it turned out that attempts to swiftly resolve the paradox do not in fact resolve it, but at best push it into the next dimension. This result speaks in favor of Carr's and Rinofner-Kreidl's claims that the paradox cannot be resolved, as well as Drummond's recognition that the relation between the two descriptions of the self remains paradoxical. This does not necessarily mean, however, that the paradox cannot be resolved in other ways. Nor does it imply that the paradox is a vicious problem or amounts to a contradiction for transcendental phenomenology. Establishing any of this, or the contrary, is not the aim of this paper. Instead of suggesting another alleged resolution, in this section I propose a new approach to the paradox of subjectivity.

Paradoxes often indicate a lack of understanding, and potentially a conceptual misunderstanding. They are exactly the kind of riddle philosophers are eager to solve, resolve, dissolve, or otherwise eliminate. It is thus understandable that this was Husserl's first impulse, and that other philosophers have since attempted to complete the resolution which Husserl himself did not clearly reach. The attempted resolutions of the paradox considered above presuppose that the paradox indicates a lack of understanding. Zahavi rightly quips that "paradoxes are not exactly the kind of things I would like to collect and hoard" (2002, p. 107). Some paradoxes, however, may also teach us something important about the issue at hand. In such cases it may be better to resist the impulse to eliminate the paradox, in favor of considering the origins of the paradox beyond any conceptual issues.

The fact that, even when it seems like there is a resolution, the paradox of subjectivity does not vanish but instead reappears in a different dimension, suggests that there is more to the paradox than just a lack of understanding, or a mere conceptual misunderstanding, or even several conceptual misunderstandings that may be involved in the different formulations of the paradox. The impulse to eliminate the paradox may stand in the way of a more comprehensive understanding of the 
subjective and objective senses of the embodied self. Hence, instead of asking how to dissolve the paradox, the question here is whether there is an underlying reason for the persistence of the paradox, a reason that is not only due to the phenomenological reduction or any other philosophical methods. Indeed, the discussion in Sect. 2 already indicated that the paradox is not limited to phenomenological, or transcendental, philosophy.

In this section I will argue that the paradox of subjectivity indicates something fundamental about the embodied self and the structure of ordinary experience. The preceding sections already took into consideration the role of the natural attitude, to which ordinary consciousness corresponds. The point here is not that there is no full-blown paradox in ordinary consciousness, but rather that, in a rudimentary form, ordinary consciousness already contains the different constituents of the paradox. There may even be, under special circumstances that do not involve the phenomenological reduction, a sense of tension or "fissure" between these constituents. The phenomenological reduction sharply distinguishes these different constituents and thereby "splits the ego" and so generates the paradox.

Husserl himself held that the phenomenological reduction does not create something in consciousness, but rather discovers it. The suspension of the general thesis under the phenomenological attitude still leaves room for an awareness of those objects whose existence in the world is alleged under the natural attitude. Specifically, someone engaging in the phenomenological reduction can become aware of herself as both an object in and a subject for the world. Husserl claims that when this happens, the phenomenological reduction "splits" the ego or self:

The phenomenological reduction thus tends to split the ego. The transcendental spectator places himself above himself, watches himself, and sees himself also as the previously world-immersed ego. In other words, he discovers that he, as a human being, exists within himself as a cogitatum, and, through the corresponding cogitationes, he discovers the transcendental life and being which make up < the > totality of the world. (Husserl 1998, p. 15; Hua I, p. 16)

Husserl states his claim that the phenomenological reduction splits the self in the active voice, which may make it seem as if this split occurs at the discretion of the phenomenological method. At the same time, however, he speaks of a twofold discovery. On the one hand, there is the discovery that the person engaging in the phenomenological reduction exists within him- or herself as a cogitatum. On the other hand, there is the discovery of "the transcendental life and being" of the subjective givenness of all cogitata, through the cogitationes that constitute the self as a subject to whom the cogitata are given. By discovering the subjective side of cognition, the person who engages in the phenomenological reduction becomes aware of the self as a subject for the world.

In addition, the same "transcendental spectator" recognizes that he or she also exists as a cogitatum within him- or herself. The cogitatum is that of a human being in the world, who is only now considered as a phenomenon, independently of the question of his or her existence in the world. The reduction does not postulate the self as an object in the world; after the reduction, the previously world-immersed self is merely a cogitatum. But since the cogitationes that make up subjectivity 
correspond to the self as a cogitatum, the self after the reduction is still the same self. The phenomenological reduction sharply distinguishes three constituents of self-experience. The first constituent (1) is the assumption of the independent existence of the objects experienced in the world, including oneself. The second constituent (2) is the subjective character of (conscious) experience. The third constituent (3) is the identification of the self of the transcendental spectator with the previously world-immersed self. Because (1) and (2) depict divergent senses of the self and (3) demands that they refer to the same self, the phenomenological reduction separates two senses of self within the same self, and hence splits the self. ${ }^{4}$ This splitting of the self between (1) an object in and (2) a subject for the world, together with (3) the identification of both as the same self, engenders the paradox of subjectivity.

Although it is the phenomenological reduction that splits the self, this split is not a free partitioning at the discretion of the phenomenological reduction, but rather uncovers what is already given in ordinary consciousness. Here, the three constituents are not sharply distinguished. The first constituent (1) dominates, due to the general thesis of the natural attitude and the assumption that the subjectively-experienced things exist independently of subjectivity. Of course, this does not eliminate the second constituent (2), the subjective character of conscious experience, but rather ignores it in favor of a seemingly purely objective view of the world. Subjectivity for the world is active in ordinary consciousness, even though it does not appear distinctly.

Since (2) does not appear distinctly, neither does the third constituent (3): the recognition that the cogitationes correspond to the self as a cogitatum. There can be instances, however, where some such recognition is implicit in experience under the natural attitude. In the mirror example mentioned in Sect. 2, I can recognize that the person in the mirror is me: not only a body in the world, but also the embodied self that is both a subject for and an object in the world. This does not mean that there is any clear awareness of oneself as a transcendental spectator, or even a sense of split. Most probably, I naturally identify the person in the mirror with myself (as an experiencing subject) without becoming aware of any difficulty. In some instances, however, identifying oneself with the object in the mirror involves a sense of unease, which may hint at the problem of identifying oneself, as an experiencing subject, with an object in the world. Other instances where there can be a sense of tension between the first two constituents under the natural attitude are considered below.

Because (2) and (3) are not clearly distinguished in ordinary consciousness, there is no clear split of the self under the natural attitude. Nevertheless, the decisive cut is already made under the natural attitude. By taking the self to be an object that can be observed from the outside, the general thesis cuts the self as an object away from the self as a subject. Because of the fundamental difference between the experience

\footnotetext{
${ }^{4}$ Husserl (Hua VIII, p. 94) also speaks of a multiplication of selves (Ichvervielfältigung) or a duplication of the self (Ichverdoppelung), which is thought to be essential to, e.g., phantasy (Bernet 2004, p. 6) and recollection (Cavallaro 2019). The metaphors of multiplication and duplication, however, suggest a replication of both the subjective and the objective side. They are thus less appropriate for the splitting of one and the same self into a subjective and an object part.
} 
of objects and pre-reflective awareness, self-observation "implies a dissociation of the self which is cut into an observing subject and an observed object"; therefore, observation can only ground the self as an object, not (subjective) self-consciousness (Legrand 2007, p. 587). By itself, this does not automatically result in a paradox, because the subjective side of experience is usually ignored under the natural attitude. Due to the natural attitude's preoccupation with external objects, the self as a subject does not appear, and thus the paradox does not become apparent either. Yet, ordinary consciousness comprises both observation and pre-reflective awareness. Since the observing subject is involved in the observation, the dissociation is implicit in ordinary consciousness under the natural attitude. While it is true that there is no clear distinction between the constituents of the paradox in ordinary consciousness, and also that the paradox becomes clear only through the phenomenological reduction or other philosophical methods, in ordinary consciousness the self as an object is separated from subjectivity, which prepares the split of the self.

A vivid description of this separation within ordinary consciousness is given by Sartre. He writes that not only self-observation but, more generally, "presence to always implies duality, at least a virtual separation" between that which is presented and the self to whom it is presented (2012, p. 77). In the case of self-awareness, the separation is part of the being of the self: "Presence to self $[\ldots]$ supposes that an impalpable fissure has slipped into being. If being is present to itself, it is because it is not wholly itself" (2012, p. 77). That the fissure is impalpable implies that there is no clear awareness of the fissure in ordinary consciousness. The reason why there is no clear awareness of the fissure was already given above: ordinary consciousness does not clearly distinguish between the person in the world and the experiencing subject. For this to constitute a paradox, however, there would need to be a sharp distinction between the different constituents. But while the paradox of subjectivity itself is not inherent to ordinary consciousness, its roots are already there, including a rudimentary form of the "constant tension" discussed in Sect. 4, which Sartre describes as a "fissure."

Although usually there is no clear awareness of the fissure, the fissure may rise to some awareness in deviant forms of consciousness. Echoing Sartre, it has been argued, with reference to psychopathological studies, that "the structure of subjectivity includes potential divisions and fissures that condition the experiences of radical self-alienation seen in schizophrenia" (Stephensen and Parnas 2017, p. 630). The idea here is not that schizophrenia is or produces the fissure, but rather that it is characterized by a special and potentially exaggerated awareness of one's consciousness, which brings to the fore the divisions and fissures that are already part of ordinary consciousness. Although there is a disturbed relation to one's own consciousness, that very disturbance reveals that ordinary consciousness is not uniform. Other disturbances of consciousness such as depression, drug use, and drug withdrawal experiences, may provide further evidence for the idea that one can become aware of the fissure under certain circumstances. Another experience that may result from the fissure is anxiety, or anguish (angoisse) under Sartre's definition (2012, p. 18), a concept he had compared to the epoche (2004, p. 28). All these cases are interpreted to be direct results of the fundamental difference between the experience of objects and pre-reflective consciousness, although again the awareness they involve does not 
clearly separate the different constituents of experience, does not distinctly recognize the self as a subject of experience, and by itself does not amount to a paradox.

The phenomenological reduction, in contrast, clearly distinguishes and recognizes all three constituents. The person engaging in the phenomenological reduction recognizes that she is aware of (1) a cogitatum that corresponds to the previously world-immersed self. She recognizes (2) the self as a subject for the world that belongs to all cogitationes. And she recognizes (3) that she as a subject for the world is the same self as the previously world-immersed self. As discussed above, this recognition of the separation results in a split of the self. The split of the self yields the two senses of self that are juxtaposed in the paradox of subjectivity: the self as an object in and as a subject for the world. The third constituent is also a precondition of the paradox, as discussed in Sect. 2 in connection with the "essential equivocation." These three constituents thus concisely bring together the determinants of the paradox that were discussed in the previous sections. By splitting the self, the phenomenological reduction generates the paradox of subjectivity.

Because the general thesis already cuts the self as an object away from subjectivity, and the three determinants of the paradox of subjectivity are, in a rudimentary form, already given in ordinary consciousness, the paradox is ultimately rooted in ordinary consciousness. This does not mean that the paradox of subjectivity itself is already inherent to ordinary consciousness. Rather, the phenomenological reduction brings to the fore the cut, dissociation, or fissure that is overlooked in ordinary experience, and is unclearly experienced in deviant forms of consciousness. Unlike many other paradoxes, the paradox of subjectivity is not due to a mere conceptual misunderstanding, but instead expresses something about ordinary consciousness. Ordinary consciousness is ambiguous, and already the general thesis of the natural attitude introduces a tension that philosophical conceptions of the embodied self must come to terms with.

\section{Conclusion}

In this paper I have taken a rather unconventional approach to the paradox of subjectivity. In the first three sections, I have systematized and discussed the different "resolutions" of the paradox of subjectivity according to the dimension each pertains to. We have seen that none of them truly resolves the paradox, but each at best pushes it into the next dimension. The proposed resolutions have been helpful, however, for clarifying the problems and concepts involved, and sharpening the nature of the paradox of subjectivity. Investigating the role of the phenomenological reduction and its relation to the natural attitude laid the foundation for identifying the three constituents of the paradox in Sect. 5. I showed that, while the paradox necessitates the sharp separation of the self as an object (1) and the self as a subject (2) - a separation that is not given clearly in ordinary experience-it is nevertheless rooted in the structure of ordinary experience. I suggested that the third constituent (3) of the paradox, the recognition that (1) and (2) are the same self, is also given in rudimentary form in ordinary experience (see Sect. 2). The fact that the paradox 
is rooted in ordinary experience constitutes an underlying reason for its persistence through different dimensions and different philosophies.

Since the embodied self is both subjectively aware of the world and objectively part of the world, the concept of the embodied self is not a simple resolution of the paradox of subjectivity, but must itself deal with it. Yet recognizing the persistence of the paradox does not mean that the concept of the embodied self is necessarily incoherent. Rather it means that the concept of the embodied self is more complex than one might first think, and that it must go beyond conventional concepts of subject or object. The division underlying the paradox cannot be resolved by conceptual means alone, because it is rooted in ordinary experience. But since ordinary experience also unites the different constituents of the embodied self, further study of ordinary experience, and how it is conceptualized in philosophical reflection, promises to shed further light on the peculiar nature of the embodied self.

Acknowledgements Several arguments of this paper have been presented at different occasions. For the discussion of those arguments and other feedback I would like to thank David Carr, Jakub Čapek, Marco Cavallaro, Maike Cram, Dorothée Legrand, Oliver Lukitsch, Tereza Matějčková, James Mensch, Graham Parkes, Matthew Ratcliffe, Line Ryberg Ingerslev, Philipp Schmidt, Dylan Trigg, and Dan Zahavi. Many thanks also to two anonymous reviewers, whose constructive criticisms have led to important clarifications. I am also grateful for the outstandingly thorough editing work by Steven Crowell and Sonja Rinofner-Kreidl. Work on this paper was supported by the European Union's Horizon 2020 research and innovation program under the Marie Skłodowska-Curie Individual Fellowship no. 701584. Open access funding provided by University of Vienna.

Open Access This article is distributed under the terms of the Creative Commons Attribution 4.0 International License (http://creativecommons.org/licenses/by/4.0/), which permits unrestricted use, distribution, and reproduction in any medium, provided you give appropriate credit to the original author(s) and the source, provide a link to the Creative Commons license, and indicate if changes were made.

\section{References}

Bernet, R. (2004). Conscience et existence: Perspectives phénoménologiques. Paris: Presses universitaires de France.

Carr, D. (1999). The paradox of subjectivity: The self in the transcendental tradition. Oxford: Oxford University Press.

Cavallaro, M. (2019). Ego-splitting and the transcendental subject: Kant's original insight and Husserl's reappraisal. In I. Apostolescu (Ed.), The subject(s) of phenomenology: Rereading Husserl. Dordrecht: Springer.

Drummond, J. J. (2002). Paradox or contradiction? Human Studies, 25(1), 89-102.

Hua I. Husserl, E. (1950). Cartesianische Meditationen und Pariser Vorträge. S. Strasser (Ed.). Dordrecht: Kluwer.

Hua III/1. Husserl, E. (1976). Ideen zu einer reinen Phänomenologie und phänomenologischen Philosophie; Buch 1, Band 1: Allgemeine Einführung in die reine Phänomenologie. K. Schuhmann (Ed.). Den Haag: Nijhoff.

Hua IX. Husserl, E. (1962). Phänomenologische Psychologie: Vorlesungen Sommersemester 1925. W. Biemel (Ed.). Dordrecht: Kluwer.

Hua VIII. Husserl, E. (1959). Erste Philosophie (1923/24): Zweiter Teil: Theorie der phänomenologischen Reduktion. R. Boehm (Ed). Dordrecht: Kluwer.

Hua XXXIV. Husserl, E. (2002). Zur Phänomenologischen Reduktion: Texte aus dem Nachlass (19261935). S. Luft (Ed.). Dordrecht: Kluwer. 
Husserl, E. (1970). The crisis of European sciences and transcendental phenomenology: An introduction to phenomenological philosophy. D. Carr (Trans.). Evanston: Northwestern University Press.

Husserl, E. (1998). The Paris lectures. P. Koestenbaum (Trans.). Dordrecht: Kluwer.

Kant, I. (1942). Kant's Gesammelte Schriften: Dritte Abteilung, Handschriftlicher Nachlass, Siebenter Band. Akademieausgabe 20. Berlin: de Gruyter.

Legrand, D. (2007). Pre-reflective self-as-subject from experiential and empirical perspectives. Consciousness and Cognition, 16(3), 583-599. https://doi.org/10.1016/j.concog.2007.04.002.

Luft, S. (2012). Husserl's method of reduction. In The Routledge companion to phenomenology (pp. 243253). S. Overgaard and S. Luft (Eds.). London: Routledge.

Rinofner-Kreidl, S. (2003). Transzendentale oder hermeneutische Phänomenologie der Lebenswelt? Über Chancen und Gefahren einer reflexiven Analyse. In Lebenswelten: Ludwig Landgrebe-Eugen Fink_Jan Patocka. Wiener Tagungen zur Phänomenologie 2002 (pp. 115-130). H. Vetter (Ed.). Frankfurt a.M.: Peter Lang.

Sartre, J.-P. (2004). Transcendence of the ego: A sketch for a phenomenological description. A. Brown (Trans.). London: Routledge.

Sartre, J.-P. (2012). Being and nothingness. H. Barnes (Trans.). New York: Open Road Media.

Seebohm, T.M. (2015). History as a science and the system of the sciences. Cham: Springer International Publishing. https://doi.org/10.1007/978-3-319-13587-8.

Stephensen, H. and J. Parnas. (2017). What can self-disorders in schizophrenia tell us about the nature of subjectivity? A psychopathological investigation. Phenomenology and the Cognitive Sciences, October, 629-642. https://doi.org/10.1007/s11097-017-9532-0.

Zahavi, D. (2002). Transcendental subjectivity and metaphysics: A discussion of David Carr's Paradox of Subjectivity. Human Studies, 25(1), 103-116.

Zahavi, D. (2014). Self and other: Exploring subjectivity, empathy, and shame. Oxford: Oxford University Press.

Publisher's Note Springer Nature remains neutral with regard to jurisdictional claims in published maps and institutional affiliations. 